\title{
AC 2009-750: EDUCATING GENERATION Y IN ROBOTICS
}

David Chang, United States Military Academy

Peter Hanlon, United States Military Academy

Kirk Ingold, United States Military Academy

Robert Rabb, United States Military Academy 


\title{
Educating Generation ' $Y$ ' In Robotics
}

\begin{abstract}
We present our approach to educating the new Generation ' $\mathrm{Y}$ ' using robotics in undergraduate education. This course is a laboratory based education for life-long learners through a look at a new course for non engineering majors in the senior year. As the centerpiece of this course, we use a robotics platform to integrate introductory programming material with electrical engineering theory. We move away from the traditional note taking and testing model as students start to become life-long learners, creators, and innovators through exposure to small scale engineering problems. The initial assessments of our approach have been very positive. Presenting students with a problem and allowing them to work in interdisciplinary groups to develop solutions using a robotics platform yielded over $70 \%$ felt they learned more, were inspired to learn and it fits the students learning style by integrating a robotics platform in their curriculum.
\end{abstract}

\section{Introduction}

Today, a majority of students in the classrooms of colleges and universities across the country were born after 1981 as Generation ' $Y$ ' or the MTV generation. An unprecedented number of these young people lived in households where both parents work or in single parent households where the single parent is employed. Generation ' $\mathrm{Y}$ ' belongs to a generation in which daycares, babysitters, televisions and peers serve as surrogate parents ${ }^{1}$. Because many of them have grown up with computers, a majority of youth in this generation are technologically literate. In fact, intrinsic to the proliferation of technology, modern tools of communication such as the internet, beepers and cell phones are social lifelines for this generation. Consequently, youth of today are more independent, resourceful and peer dependent ${ }^{2}$. They also tend to be inventive and are selfsufficient problem solvers. They often desire support and feedback, but detest authoritative control. Accustomed to immediate gratification, youth in these generations are responsive. They crave stimulation and expect immediate answers and feedback ${ }^{3}$. Recently National Academy of Engineering, Committee on the Engineer of 2020 published Educating the Engineer of 2020: Adapting Engineering Education to the New Century that offers recommendations on how to enrich and broaden engineering education so graduates are better prepared to work in a constantly changing global economy. This addressed how students learn as well as what they learn in order to ensure that student learning outcomes focus on the performance characteristics needed in future engineers. If the United States is to maintain its economic leadership and be able to sustain its share of high-technology jobs, it must prepare for this wave of change ${ }^{4}$.

Today's college students are typically very comfortable with technology, have shorter attention spans, a low threshold for boredom, resist memorization and busy work and prefer action to observation ${ }^{9}$. Learning styles of these generations are more active and visual rather than verbal. Given the distinguishing attributes of these new generations, including a highly visual imagination, educators are obliged to explore different and innovative teaching strategies that effectively address students in terms that they easily recognize and comprehend. For effective instruction to occur, the educator should traverse the world of the learner. Brown ${ }^{3}$ suggested that 
authentic learning requires the learner to communicate detailed understanding of a problem or issue rather than memorize sets of isolated facts, and must result in achievements that have relevance beyond the classroom. This paper presents a successful teaching/learning strategy applying robotics in the classroom at the United States Military Academy (USMA), which is directly geared towards Generation ' $\mathrm{Y}$ '.

\section{Background}

Robotic science and systems is a very fast growing area of research, and it has significant potential for various applications to include military, security, commercial, scientific (space exploration), academic, social, humanitarian, medical, etc. Congress has set a goal for the Armed Forces to achieve the fielding of unmanned, remotely controlled technology such that: 1) by 2010, one-third of the operational deep strike aircraft of the Armed Forces are unmanned; and 2) by 2015 , one-third of the operational ground combat vehicles of the Armed Forces are unmanned $^{10}$. In support of this, the vision of the Academy is to lead the efforts in educating and inspiring future technical leaders.

The military presently has significant interest in the field of robotics, where currently there are over 4,000 unmanned systems deployed. The main tactical advantages of using unmanned systems utilized in hostile situations is multifold: to gather information, perform inspection, deploy munitions, detect and disable ordnance in hazardous environments, maneuver in relatively small areas, be used as a decoy or be sent to draw out opponent fires without risking the life of the operator. There have also been various universities that have integrated robotics into their curriculum or developed new courses that use robotic platforms as the center piece. Weingarten, et. al. used robotics as a vehicle to engineering education and to propel the students into research and life-long learning ${ }^{5}$. Chung and Anneberg ${ }^{6}$ summarized how to use contests to stimulate learning in computer science and engineering education. Mehrl et. al. ${ }^{7}$ used an autonomous robotics capstone design project to enable students to used their preferred learning style to learn how to work as teams. Verner $^{8}$ developed an introductory robotics course that contains hands on learning experience and assessment methods. However most of these are researched based programs focused on educating engineering or computer science students. We not only use robotics platforms within our program but we also use them as tools to instruct non engineers.

The approach taken by the Department of Electrical Engineering and Computer Science (EE\&CS) begins with designing a multifaceted and dynamic educational experience for the students. The experience starts with exposure during the first field exercise when students are exposed to the utility of robotics prior to starting their freshman year. During freshman year there is an evening robotics workshop and an experimenters club that builds various robotics platforms. These events along with the guidance of faculty provide students who may be interested in Electrical Engineering and Robotics some experience in the area to make more informed decisions when selecting a major during their sophomore year. If a student chooses the Electrical Engineering and Robotics Track, they are exposed to numerous courses with many embedded robotics projects and labs during their sophomore and junior years. Also during their junior year the faculty hosts trips for the students to travel to various robotics manufacturing companies to allow students to see firsthand what industry is developing and manufacturing for 
military and commercial applications. At the end of their junior year, they could select to go on an Academic Individual Advanced Development (AIAD) internship at one of our industry partner sites to gain hands-on experience in researching, designing, or manufacturing of some of the advanced unmanned platforms deployed to various operations around the world. When the students return to start their senior year at USMA, students in the program can choose to be involved in a multi-disciplinary Robotics Capstone Design Team to further develop their technical and tactical application skills ${ }^{11}$.

Due in part to the increasing interest and involvement by students in robotics last year, robotics were used as a recruiting demonstration within the EE\&CS department for sophomores trying to decide their majors and subdiciplines. As a result, the number of students desiring to major in electrical engineering doubled, with the majority enrolling in the Robotics Track (one of five tracks offered to electrical engineering majors) as shown in Figure 1.

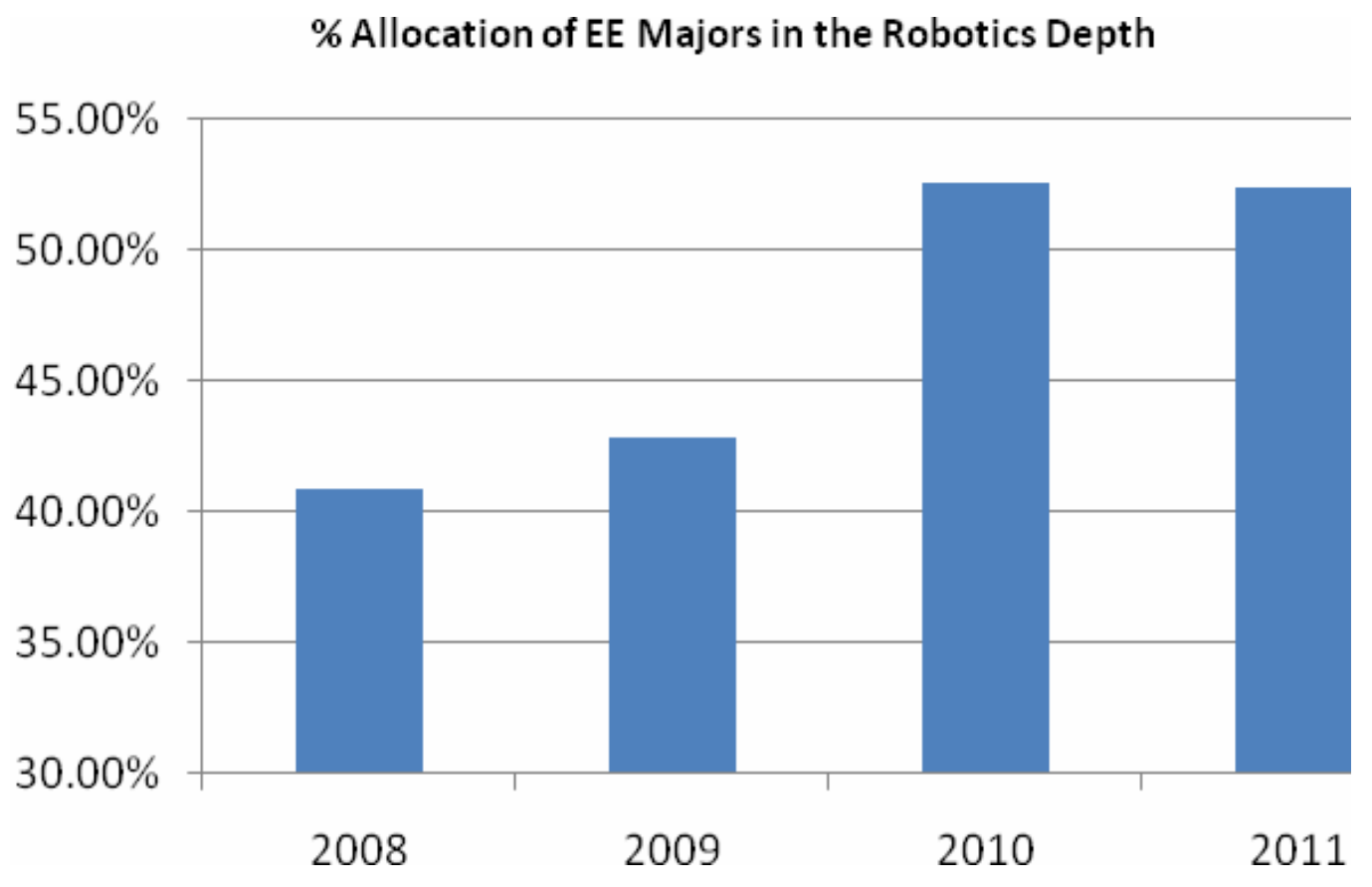

Figure 1: Percentage of EE Majors, by class year, within the Robotics Depth Track.

For students who do not major in engineering, an institutional requirement is for them to take at least three sequential engineering courses in one of the engineering departments. In the EE\&CS department, one of the three sequential courses was recently developed for the non engineering majors and is being redesigned to appeal to Generation ' $Y$.' Figure 2 shows the diversity of a recent class taking this course, Military Electronic Systems. 


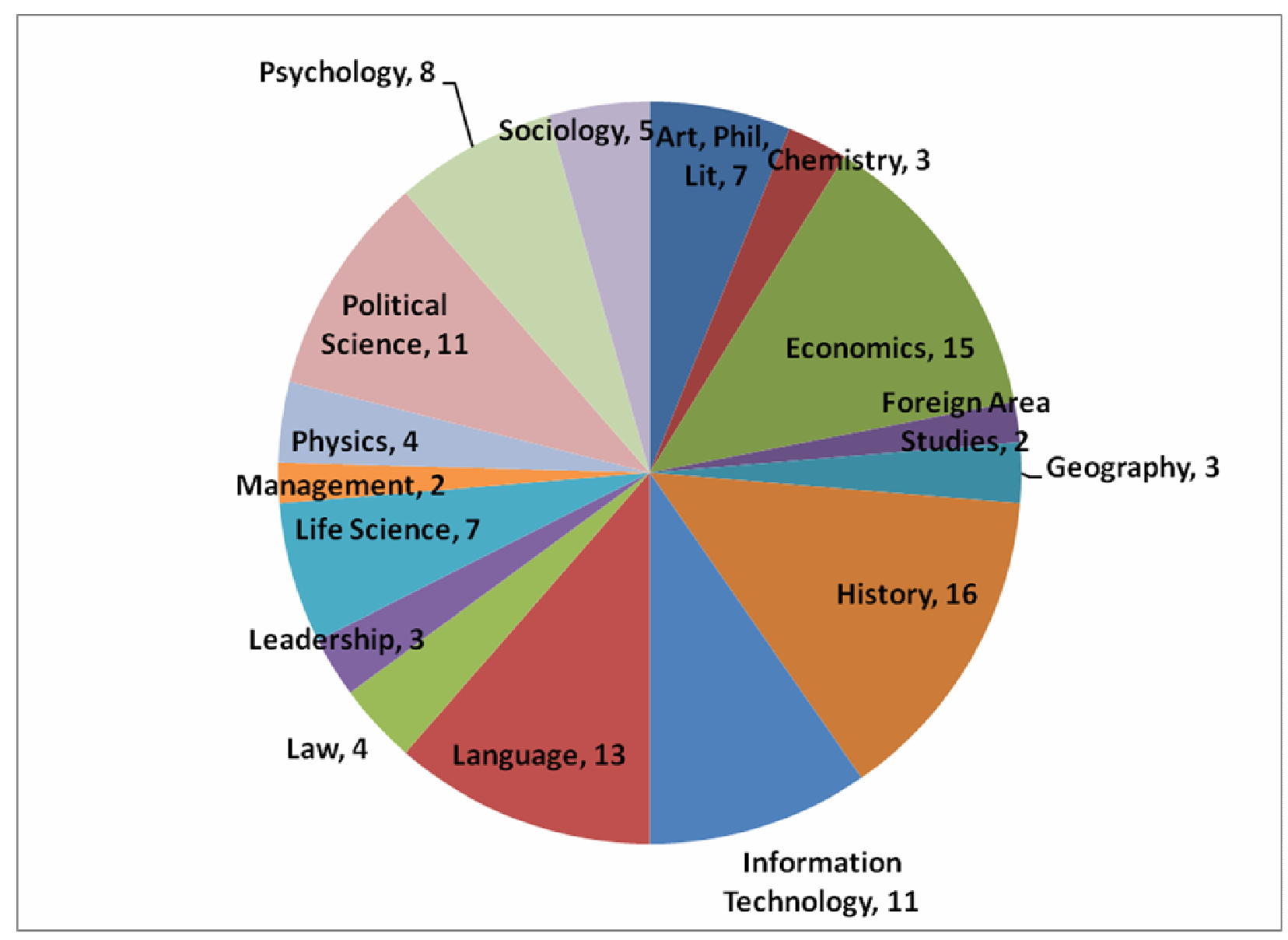

Figure 2: Number of Non Engineering Majors Enrolled in the Course

In effect, the program has redefined how to accommodate student interest as well as the potential impact upon graduates and the military significance of the robotics program itself. Presently our program is working with various companies, other universities and other government organizations to conduct joint research, develop future platforms/algorithms, and designing courses to meet the rising interest in robotics. As such, we are redesigning several courses to use one robotics platform which will assist in coupling the courses and speaks to how students both conceptualize and apply system development. This approach also provides ownership of the system and empowers the students to experiment and be creative with the system outside of the classroom.

\section{Redesigned Coursework}

One of the most important first steps to redesign a course is to understand how and why people learn, how to inspire and motivate students to learn and the various student learning styles. There are various ways of transferring knowledge from experiences, background, environment, and culture. However, it may take education and time for individuals to develop, improve, and build on this knowledge in order to apply it to a new problem or environment. In the Teacher's Wisdom "Teachers open the door. You enter by yourself" ${ }^{12}$, part of the motivation and drive to enter may come from the teacher's teaching methodology and how well the teacher understands 
the students. The understanding of students may not only be mentally, culturally, and environmentally but also biologically and emotionally. These concepts are very important for effective teaching where we are not only training particular disciplines but we are continually educating the students and ourselves on a broad spectrum of knowledge and understanding.

One of the hardest things to do in our profession is to motivate and inspire students to learn. There are numerous examples to motivate students ${ }^{13}$. The various strategies, incorporating instructional behaviors, various ways to structure the course, such as de-emphasizing grades, feedback, and preparation gives many ideas on how to implement this new course. But every teaching method carries with it inherent problems, so effective instruction uses multiple approaches. The most interesting concern from the Lang article was the conclusion of "comprehension lies outside of the classroom"14. The design of the new approach was students read material in advance, in class she would lecture highlights for 20 minutes and then students break into groups to work on the assigned homework problems. Also each student may have various learning styles and most people have many learning styles. McKeachie ${ }^{15}$ reflected that too many teachers think of students as a featureless mass; too many rarely vary their teaching methods, thinking that the method by which they were taught is best for everyone. However, learning styles are preferences and habits of learning that have been learned and that everyone is capable of going beyond the particular style preferred at the time. Also learning styles do not make as much difference as the student's prior knowledge, intelligence, and motivation and that these characteristics are learnable. So it is important for both teachers and students to realize that learners always encounter many situations that are not adapted to their own preference. But what teachers need to do is to help students develop the skills and strategies needed for learning effectively from teachers who do not match student's preferred learning style. Good teaching involves more than communicating the content of one's discipline; a good teacher also needs both to motivate students to continue learning and to teach them the skills and strategies needed for continued learning.

One of the courses that we have redesigned is Military Electronic Systems. This course originally was primarily a lecture based course that attempted to cover a wide range of topics without sufficient background or hands on material. Caudron ${ }^{16}$ suggested that the focus should be on outcomes rather than techniques. This implies that we help students put information to work, to help them do something, not only knowing something. Caudron also suggested that educators consider the following five areas when teaching these students, and many of Caudron's strategies are embodied in the redesign of this class:

(1) Make learning experiential by engaging students in role-playing and cooperative learning experiences.

(2) Give students control of their learning.

(3) Highlight key points since new learners are surfers and scanners rather than readers and viewers (e.g., the use of Power Point presentations).

(4) Motivate learning by engaging students in their own learning environment.

(5) Challenging students to construct knowledge from their experiences.

We have redesigned this course to contain four sections: a review of critical fundamental material, hands on applications on a microcontroller, sensors, and robotics platform, and a final 
design project. This robotics platform integrates various input sensors and output devices (such as LEDs, speakers, and digital displays) controlled by a microcontroller. The robotics platform allows for more experimentation and hands on learning, especially suitable for active learners. The robotics platform also makes learning interesting and fun with various transferrable skills. This course also allows the instructors to take a crawl, walk and run approach. During the crawl stage, the instructors will review the critical material focusing primarily on lectures. The walk stage lets students read and investigate possible solutions to the problem presented thus focusing on student reading and learning outside of the classroom. Finally, during the run stage the students will integrate the review and research material and discuss/apply the solution with team members to a robotics platform. This provides the students time for experimentation and teamwork. The final design project allows the students to be innovative and creative with their design. In the end, the final design project is briefed to the instructor with a demonstration of the design, explanation of plan, and an oral examination to test understanding, future implications, and critical thinking skills.

\section{Results and Discussion}

Classroom research and classroom assessment respond directly to concerns about better learning and more effective teaching. With this redesigned course we wanted to find out - how well are students learning and how effectively are teachers teaching ${ }^{17}$. Where assessment is like closing the loop or feedback from students of how you and they can use the information to improve learning, Davis ${ }^{13}$ recommends various methods to obtain feedback from students to include: minute paper, chain notes, memory matrix, directed paraphrasing, one sentence summary, exam evaluations, application cards, and student generated test questions. She also discusses strategies, tactics to increase student participation, and tactics to keep students talking. We chose to use a direct question survey to obtain feedback for classroom assessment. This redesigned course has been offered for the last two fall semesters in the redesigned format. The course was divided into two main sections- Section 1 was the traditional lecturing style instruction and Section 2 was application and project teams using the robotics platform. There were three different sections of students each semester with a range of 15-18 students per section. In fall of 2006 there were 35 students and in fall of 2007 there were 48 students that participated in the survey. The results of the survey are summarized in Table 1.

Table 1: Survey Results from Military Electronic Systems Course Fall Semester 2006 and 2007.

\begin{tabular}{|l|c|c|}
\hline & 2006 & 2007 \\
\hline Interest in area of study/ learn transferable skills & $82.86 \%$ & $81.25 \%$ \\
\hline Learned most from robotics application section & $71.43 \%$ & $85.42 \%$ \\
\hline Experimentation/ team discussions & $94.29 \%$ & $87.50 \%$ \\
\hline Inspired to learn the most from robotics section & $74.29 \%$ & $87.50 \%$ \\
\hline Active Learner & $85.71 \%$ & $89.58 \%$ \\
\hline Robotics section best fits learning style & $77.14 \%$ & $85.42 \%$ \\
\hline
\end{tabular}

The results from Table 1 show that most of the students are motivated and inspired to learn because they are interested in the subject and the subject has transferrable skills. Most of the students feel that they are active learners and that they learn best by working hands on and in 
teams. This is a good match for some of the design parameters we have used to redesign this course and the result was that most of the students thought the robotics application allowed them learn effectively, motivated them to learn, and fit their learning style.

\section{Conclusion}

In summary, we have developed an unprecedented robotics engineering experience for the students by combining course work, AIADs, capstone engineering design courses, new research, and an impressive customer base. Because we believe that robotics is a critical military asset in the future, we have also begun teaching non-technical/ non-engineering majors about electronics and systems by utilizing robotic and microcontroller platforms. Given that interest in this area of research is growing very fast everywhere, the most prominent limitations at this point have been the number of research personnel and funding to put towards this program in order to keep it relevant and of desirable quality.

Our short term goals are to evaluate existing course work and integrate more hands on experimentation and robotics that could make an immediate impact to the student's learning. Our long term goals are to continue doing faculty and student research and educate our students on the development of coordinated robotic systems to be used in future combat systems. We intend to use this knowledge to stimulate additional interest in other departments, faculty, and students to further study cooperative robotic systems as a combat multiplier and future weapon system.

As a result of the renewed emphasis in robotics for real missions, the recent successes of our collaborative efforts with industry and the subsequent positive impacts and enthusiasm regarding robotics courses, we are in the process of proposing a renovation of facilities within the Department of EE\&CS to support a robotics lab to 1) test and evaluate existing robotics systems and platforms; 2) conduct research and development of future systems in cooperative robotics; and 3 ) educate future leaders on employment and deployment of these systems.

\section{References}

1. Holtz, G. (1995). "Welcome to the jungle". New York: St. Martin.

2. Whitehead, B. (1997). "The divorce culture". New York: Alfred A. Knopf.

3. Brown, B.L. (1997). "New learning strategies for generation X". ERIC Digest, 184.

4. The National Academies, "Educating the Engineer of 2020: Adapting Engineering Education to the New Century, The National Academies Press, Washington, D. C., 2005.

5. Weingarten, Joel D., Koditschek, Daniel, Komsuoglu, Haldun, Massey, Chris, "Robotics as the Delivery Vehicle: A Contexualized, Social, Self Paced, Engineering Education for Life-Long Learners", Proceedings of the Robotics Science and Systems Conference, 2007.

6. Chung, Jin Chung and Anneberg, Lisa, "Robotics Contests and Computer Science and Engineering Education", ASEE/IEEE Frontiers in Education Conference, 2003.

7. Mehrl, David J., Parten, Micheal E., and Vines, Darrell, L.,” Robots Enhance Engineering Education”, ASEE/IEEE Frontiers in Education Conference, 1997.

8. Verner, Igor M "Conceptualising educational approaches in introductory robotics". International Journal of Electrical Engineering Education. Jul 2004. 
9. Litten, A. \& Lindsay, B. (2001). "Teaching and learning from Generation Y". A presentation for ACRL New England annual program; 2001, June 1, Brandeis University.

10. National Defense Authorization Act for FY2001 H.R. 4205 Section 217, http://www.fas.org/man/congress/2000/hr4205eas.htm, November 15, 2006

11. Chang, D., Jacoby, G. and Shay, L., 2007, "AC 2007-2208: Preparing and Advising a Fast-Track Education in Robotics", Proceedings of 2007 ASEE Annual Conference and Exposition, June 2007.

12. Marchese, Theodore J., " The New Conversations About Learning", Conference of the American Association for Higher Education in 1998.

13. Davis, Barbara G., "Tools for Teaching", Jossey-Bass Publishers, San Francisco, CA, 1993.

14. Lang, James M., "Beyond Lecturing" The Chronicle of Higher Learning, September 29, 2006.

15. McKeachie, W. J., Pintrich, P. R., and Lin, Y-G. (1985) "Teaching learning strategies." Educational Psychologist, 20(3), 153-160.

16. Caudron, S. (1997). "Can Generation Xers be Trained?" Training and Development, 3, 20-24.

17. Angelo, Thomas A. and Cross, K. P., "Classroom Assessment Techniques, A Handbook for College Teachers, $2^{\text {nd }}$ Ed", Jossey-Bass Publishers, San Francisco, CA, 1993. 